\title{
Article
}

\section{The role of beliefs and trait aggression in prison bullying among young offenders}

\author{
Adams, Christine and Ireland, Jane Louise \\ Available at http://clok.uclan.ac.uk/20251/ \\ Adams, Christine and Ireland, Jane Louise ORCID: 0000-0002-5117-5930 \\ (2017) The role of beliefs and trait aggression in prison bullying among young \\ offenders. Journal of Forensic Psychiatry and Psychology . ISSN 1478-9949
}

It is advisable to refer to the publisher's version if you intend to cite from the work. http://dx.doi.org/10.1080/14789949.2017.1395060

For more information about UCLan's research in this area go to

http://www.uclan.ac.uk/researchgroups/ and search for <name of research Group>.

For information about Research generally at UCLan please go to http://www.uclan.ac.uk/research/

All outputs in CLoK are protected by Intellectual Property Rights law, including Copyright law. Copyright, IPR and Moral Rights for the works on this site are retained by the individual authors and/or other copyright owners. Terms and conditions for use of this material are defined in the policies page.

\section{CLoK}

Central Lancashire online Knowledge www.clok.uclan.ac.uk

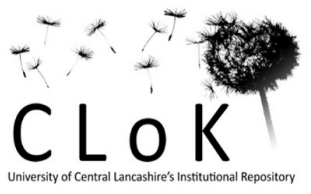


Running head: AGGRESSION, BULLYING BEHAVIOUR, YOUNG OFFENDERS, DIPC

The role of beliefs and trait aggression in prison bullying among young offenders

Christine Adams

HM Prison Service

Jane L. Ireland*

School of Psychology, University of Central Lancashire, Preston, United Kingdom

*Correspondence should be addressed to Jane L. Ireland, University of Central Lancashire and Ashworth Research Centre, Mersey Care NHS Trust, UK; TEL: +44 151473 0303; Email: JLIreland1@uclan.ac.uk 


\begin{abstract}
This study aimed to explore the characteristics of those involved in bullying, including trait aggression, beliefs, interpretation of potential threat and responses to aggression. Three hundred and thirteen young adult male offenders completed three measures; the Direct and Indirect Prisoner Behaviour Checklist, the Aggression Questionnaire, and the Threat Appraisal of Behaviour measure. Pure bullies and bully-victims were predicted to have higher trait aggression scores, and to be more likely to endorse beliefs supportive of aggression than other groups. Bully-victims were predicted to have higher levels of trait hostility and higher levels of fear than pure bullies. The results demonstrated that both bully groups had higher trait aggression scores, with bully-victims having higher scores on the hostility subscale than pure bullies or those not involved. Bully-victims viewed bullying as more of a threat and were more fearful of it than pure bullies and they were also more likely to endorse both aggressive and avoidant coping responses whereas pure bullies were more likely to endorse aggressive responding. Findings highlight differences between the two bully groups and offers an outline of the underpinning causes of bullying for each group.
\end{abstract}

Keywords: DIPC; bullying; young offenders; AQ; prisoners 
The role of beliefs and trait aggression in prison bullying among young offenders

Ireland and Ireland (2008) suggest prison bullying may be best thought of as 'intra-group' aggression, avoiding use of the term bullying, which appears to present with difficulties in measurement due to its emotive connotations (Ireland \& Ireland, 2008). Levels of reported perpetration and victimisation in prisons can be high, with one study reporting $59 \%$ of participants engaging in at least one behaviour indicative of bullying perpetration and $79 \%$ at least one behaviour indicative of victimisation (Ireland, 2011). Similar high levels have been replicated in other studies (e.g. Viljoen, O'Neill \& Sidhu, 2005; Grennan \& Woodhams, 2007; Turner \& Ireland, 2010), whilst other studies have demonstrated more conservative estimates of both bullying perpetration and victimisation (Power, Dyson \& Wozniak, 1997; Ireland \& Qualter, 2008; Holland, Ireland \& Muncer, 2009). Estimates can also differ based on the populations sampled and the different measures used (Ireland, 2005), with a general acceptance that bullying is higher among young offenders than adults (Ireland, 2012).

Bullying can include both direct and indirect aggression (Ireland, 2005). Direct behaviours are those in which the behaviour clearly has aggressive intent and is easily observable, for example physical or verbal aggression. Indirect behaviours are more covert and less easily identifiable, such as gossiping, or ostracising (Ireland, 2005). Indirect behaviours generally occur more frequently, especially within adult populations (Ireland \& Qualter, 2008; Turner and Ireland, 2010; Holland et al., 2009; Ireland, 2011). Juvenile and young offenders are argued to use more direct behaviours than adults, though these results are often inconsistent (Ireland, 2005; Chan \& Ireland, 2009). Ireland and Monaghan (2006) argue that indirect aggression is particularly effective within a prison population as it reduces the perpetrators chances of being caught and punished, as opposed to the more observable direct behaviours. 
Prisoners may therefore learn the value of utilising more indirect methods, based on their environment.

Self-report measures have identified four distinct groups of individuals, based on the behaviour they report engaging in. These consist of 'pure bullies' who only report engaging in the perpetration of bulling, 'pure victims' who only report victimisation, 'not involved' who report neither victimisation or perpetration, and 'bully-victims' who report being both a victim and perpetrator of bullying behaviours (Power et al, 1997; Ireland, 2002; Grennan \& Woodhams, 2007; Viljoen et al, 2005; South \& Wood, 2006). Prevalence rates tend to be consistent, with studies reporting prisoners more likely to be classified as 'bully-victims' and those 'not involved', with 'pure victims' and 'pure bullies' the least reported (Ireland, 2002).

Regarding why bullying takes place, the second author proposed an Interactional Model (IM; Ireland, 2002) examining the importance of both environmental factors (e.g. restriction on material goods, importance of status) and individual factors (e.g. beliefs, social skills, time in prison), suggesting that bullying behaviour can be viewed as an interaction between these. The environment positively reinforces subsequent bullying where victims, for example, are unlikely to report bullying. Research findings have supported this model, indicating an interaction between environmental factors and bullying behaviour (Allison \& Ireland, 2010) and the importance of social status (South \& Wood, 2006). Research has also increasingly been examining the role of cognitions (e.g. attitudes and beliefs: Archer \& Haigh, 1997; South \& Wood, 2006; cost-benefit analysis of actions: Archer \& Southall, 2009), leading to the IM being revised to integrate general theories of aggression more broadly (Ireland, 2012). The Multifactor Model of Bullying in Secure Settings (MMBSS; Ireland, 2012) is a development of the Interactional Model and specifies two distinct routes towards perpetrating aggression based on the environmental context. The first pathway - the 'desensitisation pathway' - occurs in an aggressive environment where the individual feels at 
increased threat of being aggressed against but perceives limited means of managing this. The individual becomes desensitised to aggression, exaggerating the attitudes and beliefs they hold supporting aggression use. When emotions such as fear, hostility or stress are then experienced the possibility of violence increases. The second pathway - the 'environment and prior characteristic pathway' - is driven more by the traits of the individual who is already predisposed towards the use of aggression. Within the prison environment individual traits linked to aggression are exaggerated, increasing the likelihood they will utilise aggressive responses (Ireland, 2012).

Both the Interactional Model and the Multifactor Model of Bullying in Secure Settings thus place emphasis on a role for both the individual and their environment, focusing on the interaction between the two. This concept is also a feature of other related models developed by the same research team, seeking to explain aggression in prison, such as the Applied Fear Response Model (APR; Ireland, 2005) and the Applied Social Information Processing Model (ASIPM; Ireland \& Murray, 2005). The Applied Fear Response Model outlines how an individual's threat response (e.g. flight or fight) can explain the adoption of either aggressive or avoidant behaviours in a prison. The Applied Social Information Processing Model is based on Huesmann's Information Processing Model of Aggression (Huesmann, 1998). It purports that within a threatening environment, such as a prison, individual's social cognitive processing is simplified and they resort to their dominant response when faced with conflict, be this aggression or avoidance. The adoption of aggressive responses can often be an adaptive response for prisoners, and the environment further positively reinforces this (Ireland \& Murray, 2005).

Differences in those involved in bullying have largely been explored between individuals classed as pure bullies and those classed as bully victims. Research has explored differences in attitudes towards aggression and an individual's attributions of cause with 
regards to their aggression. Both pure bullies and bully-victims have consistently been shown to utilise more aggressive responses and to endorse aggressive attributions more than pure victim groups (e.g. Ireland \& Archer, 2004; Archer, Ireland \& Power, 2007; Palmer \& Thakordas, 2005; Turner \& Ireland, 2010). This suggests that those involved in bullying may be more likely to demonstrate aggressive behaviour generally. Bully-victims have demonstrated more reactive, emotionally motivated, responses to aggression than pure bullies (Ireland, 2004) and higher levels of trait hostility (Palmer \& Thakordas, 2005; Holland et al, 2009), which may be due to them having more reactive attributions within situations (Holland et al., 2009). Other studies have argued that bully-victims have equally as many proactive (i.e. more calculated) attributions as reactive (Archer et al., 2007), suggesting that aggressive behaviour from this group may not be entirely reactive in nature and that the use of aggression may also be used to serve a more calculated purpose.

Whilst the behaviour of bully-victim' may not be entirely reactive, the role of emotions, in particular fear, has been argued to drive their aggressive responses towards victimisation (Ireland, 2004). Bully victims have, for example, demonstrated higher levels of fear than the other groups, with this found across prisoner populations (Ireland \& Power, 2009; Chan \& Ireland, 2009). Fear was shown to predict more emotional and help-seeking behaviours (Chan \& Ireland, 2009), and to be a mediator between an individual's experience of victimisation and their psychological distress (Ireland \& Power, 2009). This links to the Applied Fear Response model, which highlights fear as a driver in the selection of aggressive behaviour.

The role of both cognitions and emotions are arguably interlinked, an issue recognised in the prison bullying literature when trying to understand engagement in perpetration (e.g. López-Pérez, Hanoch, Holt \& Gummerum, 2015). Thus, considering cognition and emotions together is useful when considering their impact on behaviour. Protection Motivation Theory 
(PMT; Norman, Boer \& Sedel, 2005) is perhaps a further useful theory to account for. It indicates that in order for behaviour to change in response to fear, an individual must appraise the threat (e.g. the likely severity and their perceived vulnerability), and their coping ability (e.g. their belief their response will work and that they can implement it). Ireland (2011) explored the role of threat and coping appraisal in prison bullying behaviour and found that coping and threat appraisal were predictors of a fear of victimisation. Whilst both pure bullies and bully-victims were likely to choose aggressive responses and believe that others would also endorse them (normative beliefs), bully-victims had difficulty in appraising their coping ability. They were less likely than pure bullies to believe that their chosen response would work and less confident in using it, leading to higher levels of fear. This also links to the Multifactor Model of Bullying in Secure Settings, which highlights the role of both cognition and emotion in one of the pathways towards bullying perpetration. Ireland (2012) suggests that the 'desensitisation' pathway may explain bully-victims and the influence of the environment, cognitions, and emotions in shaping their responses to threat. In contrast, pure bullies may be explained by the 'environment and prior characteristic' pathway, where existing personality traits are promoted by the environment leading to the adoption of aggressive responses.

The current research examines the different characteristics of both 'pure bullies' and 'bully/victims' in a young offender sample with regards to their individual characteristics, specifically trait aggression, beliefs and their considered responses to aggression. Young offenders were selected owing to their reported increased levels of bullying in comparison to adult offenders. The following hypotheses were proposed;

1. Trait aggression will be higher in those classed as bully/victims and pure bullies compared to those classed as pure victims and not involved based on previous 
findings suggesting both of these groups demonstrate higher levels of trait aggression than others (e.g. Ireland \& Archer, 2004; Palmer \& Thakordas, 2005)

2. Those classed as bully/victims will score higher on measures of hostility than the other groups, based on research demonstrating this group demonstrates more hostility than other bully-groups (e.g. Palmer \& Thakordas, 2005).

3. Those classed as bully/victims will be more likely to report higher levels of fear and threat appraisal than those classed as pure bullies, in line with the Applied Fear Response model (Ireland, 2005) and the Multifactor Model of Bullying in Secure Settings (Ireland, 2012).

4. Those classed as pure bullies or bully-victims will be more likely to endorse aggressive responses to threat than pure victims or those not involved. This is in line with previous research (e.g. Ireland, 2011, Archer et al., 2007), which indicates both bully-victims and pure bullies are more likely to select aggressive responses.

5. Those classed as either pure bullies or bully/victims will be more likely to demonstrate normative beliefs supporting the use of violence than pure victims or those not involved. This is in line with previous research indicating both groups are likely to endorse normative beliefs supporting aggression (e.g. Ireland, 2011).

Method

\section{Participants}

Four hundred and twenty-six male young adult prisoners from a young offenders' establishment were invited to take part. A total of 347 questionnaires were returned, with 313 containing completed measures, representing a $73.5 \%$ return rate. Participants' mean age was 19.1 years (SD 2.1). A total of $81.5 \%$ classed their ethnicity as white, $4.5 \%$ as Asian, $5.1 \%$ 
black, $4.5 \%$ mixed race, $2.2 \%$ as another ethic group, and $2.2 \%$ did not specify. The majority of the sample (44.7\%) was convicted for an acquisitive offence (e.g. theft, burglary). The remaining sample were convicted of violent offences (23.6\%), drug offences $(9.6 \%)$, other offences (18.9\% e.g. arson, motoring offences), with 3.2\% not specifying. The mean sentence length was 5.9 years (SD 1.9) and the mean total length of time spent in prison was 3.2 years (SD 1.7).

\section{Materials}

All participants completed the following:

The Direct and Indirect Prisoner Behaviour Checklist - revised (DIPC-R@ Ireland 2002a). The DIPC-R identifies two types of aggression; direct and indirect. It captures both selfreported victims and perpetrators of bullying. Participants mark statements they have either experienced or engaged in within the past week. Items indicative of 'being bullied' include "I have been kicked or hit by another prisoner" and "I have been called names". Items indicative of 'bullying others' includes "I have physically threatened another prisoner with violence" and "I have made fun of another prisoner". This measure was used to categorise the sample into different bully groups.

Aggression Questionnaire (Buss and Perry, 1992). This measures trait aggression, which Buss and Perry (1992), describe as having four components; physical aggression ("I have threatened people I know"), verbal aggression ("I tell my friends openly when I disagree with them"), anger ("I have trouble controlling my temper"), and hostility ("I sometimes feel 
people are laughing at me behind my back"). Items are scored on a Likert scale where $1=$ extremely unlike me and $5=$ extremely like me.

Threat Appraisal of Behaviour - Revised (TAB-R; Ireland, 2011). The TAB-R lists a number of behavioural responses to bullying behaviour in prison including aggression towards others, avoidance, seeking help, and self-injury. Respondents are asked to indicate which behaviour they would be most likely to use, and also how they felt others would behave in that situation. In addition, they are asked to rate the behaviours for their likely helpfulness on a Likert scale, with $1=$ not helpful at all, and $4=$ very helpful. Questions also assess respondent's perceived vulnerability to being a victim of physical, verbal, psychological, sexual, theft-related, and indirect bullying and the perceived severity of this.

\section{Procedure}

Ethical approval was gained from the prison via local ethical approval procedures and by the University of Central Lancashire. Prisoners were approached whilst on 'lock-up' (i.e. all residing within their cells with no free movement on the wing) and asked to participate. If initial consent was provided a questionnaire was placed under the cell door with a blank envelope for the return of completed questionnaires. This was to protect anonymity. Participants could still not consent to engage as they were provided with additional information with the questionnaires to aid their consent further. They could in this instance return them incomplete in the envelope provided. Questionnaires were collected approximately 1 hour later via prisoners placing the blank envelope under the cell door. Results were analysed using SPSS. 


\section{Results}

\section{Data Screening}

Missing data was random; Little's MCAR test was non-significant $\left(\chi^{2}(28)=995.65, \mathrm{p}>.05\right)$ and therefore missing data from the AQ scale $(n=57)$ was replaced via Estimation Maximisation. In total, $17.1 \%$ of the TAB-R questionnaire was missing. Due to the nature of this questionnaire missing items were not replaced.

Nature and extent of reported bullying behaviours

Forty-six percent of prisoners reported at least one behaviour defined as 'bullying others' in the last week. In total, $38.3 \%$ of behaviours identified were classed as indirect bullying and $31.3 \%$ as direct bullying. Of the different types of bullying, $21.7 \%$ reported behaviours consistent with verbal bullying, $16.3 \%$ physical bullying, $15.3 \%$ theft related bullying, $8.6 \%$ psychological bullying, $6.1 \%$ coercive bullying, and $2.6 \%$ sexual bullying.

Forty-six percent reported behaviours defined as 'being bullied' in the last week. More indirect victimisation $(39.6 \%)$ was reported than direct victimisation $(28.1 \%)$. Across the different types of bullying, $17.9 \%$ described behaviours consistent with verbal bullying, $17.6 \%$ theft related bullying, $13.1 \%$ physical bullying, $7.7 \%$ psychological bullying, $6.4 \%$ coercive bullying, and $4.6 \%$ sexual bullying. 


\section{Groups involved}

Participants were placed into one of four categories based on reported behaviours: pure victims, pure bullies, bully/victims, and not-involved. Pure victims identified at least one behaviour indicative of being bullied on the DIPC-R but none indicative of bullying others; pure bullies identified at least one behaviour indicative of bullying others, but none indicative of being bullied; bully-victims identified at least one behaviour indicative of both bullying others and being bullied; with those not involved identifying no behaviours relating to being bullied or bullying others. Across the sample $37.4 \%$ were classed as not-involved $(\mathrm{n}=117)$, $28.1 \%$ as bully-victims $(\mathrm{n}=88), 17.6 \%$ as pure victims $(\mathrm{n}=55)$ and $16.9 \%$ as pure bullies $(\mathrm{n}$ $=53)$.

Aggression measures: $A Q$ and DIPC-R

Cronbach's Alpha indicated a good level of reliability on the total AQ measure $(\alpha=.93)$, with good reliability across the subscales; anger $(\alpha=.80)$, physical aggression $(\alpha=.83)$, hostility $(\alpha=.82)$, and verbal aggression $(\alpha=.79)$. Table 1 highlights the mean scores obtained on the AQ overall and across bully groups.

\section{<<INSERT TABLE 1 HERE >>}

A One-way ANOVA highlighted a significant difference on the total AQ scores across bully groups $(F(3,312)=8.5, p=<.01)$. Post-hoc Scheffé indicated pure bullies presented with significantly higher trait aggression than those not involved, with bully-victims showing 
higher levels of trait aggression than pure victims. The effect size, calculated by eta-squared, was .07 suggesting a moderate effect.

A MANOVA indicated a significant main effect on AQ subscales across bully group $(F(12$, $924)=6.1, p=>.01)$. Univariate test using Pillai’s Trace demonstrated significant differences across subscales of; anger $(F(3,309)=4.2, p=<.01$, partial eta squared $=.04)$, verbal aggression $(F(3,309)=5.0 p=<.01$, partial eta squared $=0.4)$, physical aggression $(F(3,309)=9.8, p=<.01$, partial eta squared $=.09)$ and hostility $(F(3,309)=12.3, p=<$ .01 , partial eta squared $=1.1)$. Only small effect sizes were noted for subscales of anger and verbal aggression, with larger effect sizes for physical aggression and hostility. Post-hoc Scheffé indicated that bully-victims demonstrated significantly higher scores than pure victims on physical aggression and verbal aggression. They also scored higher on hostility than pure bullies and those not involved. Pure bullies also showed higher physical aggression scores than pure victims and those not involved.

\section{TAB-R: Threat appraisal behaviour measure}

Results from the TAB-R will firstly examine threat appraisal across bully groups (i.e. how they would response to a threat of bullying and consider others to respond to this), then differences across bully groups concerning how they would consider coping, and finally differences in how each groups felt others would respond to bullying behaviour. Table 2 summarises the differences regarding how the threat of bullying would be considered by them and others, how they would consider they could cope with this, and normative beliefs across bully group and overall. 
$<<$ INSERT TABLE 2 HERE >>

Perception of the risk of being bullied and responding to a bullying threat

Across the total sample, $26.8 \%$ felt they were likely to be bullied. A One-way ANOVA was conducted to explore differences across bully groups. Pillai's Trace indicated a significant difference $(F(3)=18.74, p<.01)$ with large effect sizes (eta-squared $=0.16)$. Post hoc Scheffé tests indicated that pure victims were significantly more likely to feel they would be bullied compared to bully-victims, pure bullies and those not involved. Bully-victims were also more likely to perceive threat than pure bullies and those not involved.

Twenty-six percent of the sample felt fearful of being bullied. A one-way ANOVA (Pillai's Trace) indicated a significant difference across the different bully groups $(F(3)=14.89, p<$ .01). Post hoc Scheffé indicated that pure victims were more fearful of being bullied than bully-victims, pure bullies and those not involved. Bully-victims were more likely to fear bullying than pure bullies and those not involved.

\section{Helpful responses to bullying}

A MANOVA indicated a significant main effect in the perceived helpfulness of responses across bully group $(F(39,726)=1.42 p<.05$ : see Table 2$)$. Post hoc Scheffé indicated pure victims were more likely to identify avoidant strategies more helpful than those not involved. This included staying in their cell, avoiding contact, and giving up. Bully-victims were more likely to view acting tough and aggressing against another prisoner as more helpful than those classed as not involved. 
A further MANOVA indicated significant main effects across the response bully groups were likely to choose $(F(39,702)=1.9 p<.01)$. Post hoc Scheffé showed that pure victims were more likely to select avoidant strategies than those not involved, including staying in their cell and giving up. Pure bullies were more likely to select aggressing against the bully than pure victims and bully-victims, with bully-victims more likely to seek help from other prisoners than pure victims.

$\underline{\text { How others would behave - normative beliefs }}$

A MANOVA indicated significant main effects in relation to normative beliefs across bully groups $(F(39,637)=1.5, p<.05)$. Univariate tests using Pillai's Trace are indicated in Table

2. Post hoc Scheffé demonstrated bully-victims were more likely to feel others would aggress against another prisoner than pure victims and those not involved. Bully-victims were also more likely to feel others would seek help from other prisoners than pure bullies and those not involved.

\section{Discussion}

Just under half the sample reported engaging in behaviours consistent with bullying others, with the same proportion indicating being victimised. These proportions are lower than those reported in previous research, particularly in relation to levels of victimisation (Ireland, 2011; Allison \& Ireland, 2010). However, regarding bully category, the proportions of prisoners in each bully group was in line with previous research findings (Ireland, 2011).

There were differences in trait aggression between the different bully groups. Both bully-victims and pure bullies presented with higher trait aggression than those not involved. This is in line with previous research (Ireland \& Archer, 2004; Archer, Ireland \& Power, 
2007; Palmer \& Thakordas, 2005; Turner \& Ireland, 2010). Bullying behaviour could therefore represent a simple extension of an existing tendency towards being aggressive, which is then facilitated by the specific nature of the environment and situations presented. The existence of trait aggression as a feature would seem to support the environment and prior characteristic pathway model of the Multifactor Model of Bullying in Secure Settings, extended to cover both bullies and bully-victims (Ireland, 2012).

Hostility was also demonstrated to be an important element; bully-victims presented with higher trait hostility than pure bullies and those not involved. This generally supported the prediction that bully-victims would be the most hostile group, though no significant difference was noted with pure victims. The finding, however, that hostility was associated with a perpetrator group was again consistent with expectations of the Multifactor Model of Bullying in Secure Settings (Ireland, 2012) in that the presence of hostility, alongside other factors, can increase the likelihood of individuals becoming perpetrators.

This is particularly the case for bully-victims who are thought more influenced by the emotional components of the Multifactor Model of Bullying in Secure Settings (Ireland, 2012), of which hostility could form part. Indeed, an increase in hostility in those victimised is thought a potential driver in moving victims of bullying towards perpetrating against others (Palmer \& Thakordas, 2005). This may explain the lack of significance between bully-victim and pure victim groups within this sample, as both groups have experience of being victimised against others but only one is also displaying perpetration behaviours (bullyvictims). It could be that those currently classed as pure victims could move to bully-victims in line with the 'desensitisation' pathway on the Multifactor Model of Bullying in Secure Settings as hostility levels increase, but this could only be tested using a longitudinal design. Currently it can be argued that bully-victims are associated with higher levels of hostility and 
this potentially lends support to the suggestion that their aggression may be more reactive (emotional) in nature (Ireland \& Ireland, 2008; Ireland, 2012).

Another clear difference amongst bully groups was their experience of fear. As an emotion this was an important component to capture; bully-victims viewed bullying as more of a threat than pure bullies and reported being more fearful of it. This suggests that bullyvictims' appraisal of threat and the fear they experience is an important factor that distinguishes them from those classed as pure bullies. This is consistent with the prediction that those classed as bully/victims would be more likely to report higher levels of fear and threat appraisal than those classed as pure bullies. It supports previous research (Ireland \& Power, 2009; Chan \& Ireland, 2009; Ireland, 2011) and both the Applied Fear Response model (Ireland, 2005) and the Multifactor Model of Bullying in Secure Settings (Ireland, 2012) models; the Applied Fear Response model outlines fear as a motivating factor for a range of responses in those victimised (including aggression), with the Multifactor Model of Bullying in Secure Settings highlighting the role of negative emotions (such as fear) in the bully-victim group as an important element in moving them from those victimised to perpetrators. Thus fear and threat attribution could be considered the motivating elements for the aggression displayed by bully-victims. The finding that both hostility and fear were shown to be highest in the bully-victim group, lends particular support to the 'desensitisation' pathway in the Multifactor Model of Bullying in Secure Settings and a means of possibly explaining the different drivers for violence between those who are both perpetrators and victims and those who solely perpetrate against others.

The chosen responses to bullying also differed across groups. Pure victims selected more avoidant responses and pure bullies more aggressive, partially supporting the prediction that the latter would be more likely to endorse aggressive responses to threat, but not extending to bully-victims and those not involved. Indeed, the endorsement of such 
responses appeared more focused on pure bullies. However, bully-victims were more likely to select 'acting tough' than other groups, suggesting that an aggressive front was adopted within the prison context. It could be speculated that this was a means of securing protection rather than representing a true reflection of their character. The concept of adopting a role in prisons as a means of securing protection has been reported previously and referred to as 'role-playing' (Ireland, 2002). If accounting for the importance of social status as a characteristic driving bullying (South \& Wood, 2006), it could also allow for victims or potential victims to protect themselves through the generation of status.

Prior research has noted the importance of attitudes and beliefs (e.g. Power et al, 1997; Archer \& Haigh, 1997; South \& Wood, 2006), a potential mediating role for emotions such as empathy (López-Pérez et al, 2015), and cost-benefit analyses (Archer \& Southall, 2009) in promoting the perpetration of bullying. The current study suggests the role of cognition can also be extended to consideration of normative beliefs; these beliefs were generally in line with the behaviours each group considered helpful; bully-victims possessed normative beliefs regarding the effective use of aggression, but were also more likely to view others as expecting them to engage in help-seeking behaviour than pure bullies were. These findings partially support the prediction that those classed as either pure bullies or bully/victims will be more likely to demonstrate normative beliefs supporting the use of violence than pure victims or those not involved (Ireland, 2011), but clearly was not extended to pure bullies. It does, nevertheless, highlight how bully groups would select more aggressive responses and possess normative beliefs supporting their use of aggression. In addition, the findings also indicated that bully-victims might utilise a range of coping strategies other than aggression to manage perceived threat, such as seeking help.

This begins to develop a profile of bully-victims as those who are prone to hostility and emotional challenges, struggling to cope, are willing to use a range of coping strategies 
but perhaps gravitate towards aggression when these are not productive or possible to enact. Clearly this is speculative but is an area that future research could consider through adoption of a longitudinal design. The Multifactor Model of Bullying in Secure Settings (Ireland, 2012) also describes a process of desensitisation caused by the environment and individual factors that is important to account for. It may be that whilst bully-victims in this sample fear the threat of violence, an aggressive response is not something they are yet desensitised to utilising. Pure bullies, with existing characteristics promoting the use of violence, would arguably not require the same process of desensitisation (Ireland, 2012) and would therefore be expected to select aggressive responses within a threat-prone environment such as a prison. In addition, the Applied Fear Response model (Ireland, 2005) would suggest a range of responses to perceived threat, including both avoidant and aggressive. Bully-victims, in line with the Applied Fear Response model, appear to utilise both of these responses as a means of coping, rather than opting for a solely aggressive response. The differences highlighted between the different bully group beliefs regarding appropriate responses and normative beliefs appear to support the two distinct pathways within the Multifactor Model of Bullying in Secure Settings as a means of explaining the different factors leading to bullying perpetration in prisons.

There are, however, limitations that the current study needs to acknowledge. This is a cross-sectional non-longitudinal study ensuring therefore that causal conclusions cannot be drawn. There was also reliance on self-report, which is undoubtedly limited by an individual's honesty and insight. Within secure settings, admitting to engaging in aggressive behaviour can result in punishment and may therefore impact on how open prisoners feel they can be. Whilst questionnaires have been shown to promote more candid responses in exploring bullying behaviour (Dyson, 2005), the potential of social desirability cannot be ruled out. The use of a questionnaire may also have excluded prisoners with lower levels of 
literacy. Whilst measures previously used with prison samples were selected, it is unlikely that individuals with low literacy levels are represented within the sample due to the level of reading ability required. The sample is also obtained only from one establishment; thus the generalisability of the findings is perhaps limited to young adult male offenders.

Despite limitations, the study has contributed to the research base examining individual characteristics between bully groups. Findings demonstrate differences in the experiences of fear and levels of hostility in pure bullies and bully victims, highlighting the potential differences in drivers for aggressive behaviour between these groups. Bully-victims were also shown to endorse a number of responses to perceived threat rather than solely aggressive responses. These findings lend support to the Multifactor Model of Bullying in Secure Settings, which suggests different pathways towards perpetration for the two bully groups, particularly by accounting for factors examining individual differences. Further research could expand this study to examine how prisoner's perceptions may change over time, thus including a longitudinal component. This would allow further examination of the potential process of 'desensitisation' to violence that is argued to occur within bully-victim groups and aid an assessment of whether attributions and appraisals change over time. Additionally, whilst this study has highlighted hostility as an important characteristic of the bully-victim group, measures of trait hostility were used. Examination of whether there are also differences in state hostility would allow a more comprehensive exploration of the emotional factors within the Multifactor Model of Bullying in Secure Settings and how these apply to the different bully groups involved.

Whilst accepting the limitations, some suggestions for intervention can be made. The results indicate that those involved in the perpetration of bullying, either as pure bullies or bully-victims, should be recognised to have pre-existing elevated levels of trait aggression compared to the other groups. Intervention therefore should capture the origins of these 
raised levels of trait aggression and the factors that have facilitated and maintained them. This can be extended with bully/victims to capture the origins of their hostility and fear of harm and how this is associated with any attributional biases or errors they are experiencing. As part of this, intervention could also capture a role for emotional regulation and how to manage emotions sufficiently, to avoid them negatively influencing decision making. The findings also note how capturing and challenging the normative beliefs held by those involved in bullying would be of value. Identifying the importance of not assuming that the perpetrators of aggression will always seek an aggressive solution to actual or perceived threat, encouraging staff instead to recognise instead that some (e.g. bully-victims) will also try to employ help-seeking strategies is also important. All of this is taking place, however, within the context of a challenging environment that serves both as a causal and maintaining factor for bullying. Adopting individual-pathology led approaches to dealing with bullying should not be expected to have an impact that exceeds an approach that accepts instead that any apparent individual differences are occurring within a challenging environment. The environment thus becomes equally important to address, if not more so, that focusing on individual differences alone.

\section{References}

Allison, M.D. and Ireland, J.L. (2010) Staff and prisoner perceptions of physical and social environment factors thought to be supportive of bullying: The role of bullying and fear of bullying. International Journal of Law and Psychiatry, 33, 43-51.

Archer, J. and Haigh, A. (1997), Beliefs about aggression among male and female prisoners. Aggressive Behaviour, 23: 405-415.

Archer, J., Ireland, J.L. \& Power, C.L. (2007) Differences between bullies and victims, and men and women, on aggression related variables among prisoners. British Journal of Social Psychology, 46, 299-322. 
Archer, J. and Southall, N. (2009), Does cost-benefit analysis or self-control predict involvement in bullying behavior by male prisoners? Aggressive. Behaviour, 35: 3140.

Buss, A.H., and Perry, M. (1992). The Aggression Questionnaire. Journal of Personality and Social Psychology, 63, 3,452-459.

Chan, J. and Ireland, J.L. (2009) Fear of bullying among adult, young and juvenile prisoners: Its association with perpetration, victimisation and behavioural predictors. International Journal of Prisoner Health, 5, 4, 223-232.

Dyson, G. (2005) Approaches to examining bullying among Young Offenders within an institutional environment: Triangulation of questionnaires and focus groups. In Ireland, J. L. (Ed.), Bullying among prisoners: Innovations in theory and research, Hove: Willan Publishing.

Grennan, S. and Woodhams, J. (2007). The impact of bullying and coping strategies on the psychological distress of young offenders. Psychology, Crime \& Law, Vol. 13: 487 504.

Holland, D., Ireland, J.L., and Muncer, S. (2009) Impulsivity, attribution, and prison bullying: Bully-category and perpetrator-victim mutuality. International Journal of Law and Psychiatry, 32, 84-91.

Huesmann, L.R. (1998) The role of information processing and cognitive schema in the acquisition and maintenance of habitual aggressive behaviour. In Geen, R.G. and Donnerstein, E. (Eds) Human aggression: theories, research, and implications for social policy. London: Academic Press Ltd.

Ireland. J (2002) Bullying among prisoners. Evidence, Research and Intervention Strategies. Brunner-Routledge. 
Ireland. J (2002a) Direct and Indirect Behaviour Checklist - Revised (DIPC-R) Unpublished Report, University of Central Lancashire, Preston, UK.

Ireland, J. L. (2004) Understanding proactive bullies: Applied research in a forensic setting. Paper presented at the XVI World Meeting of International Society for Research into Aggression (ISRA), Santorini, Greece

Ireland (2005) (Ed) Bullying in Prison: Innovations in research and theory. Devon: Willan Publishing.

Ireland, J.L. (2011) The importance of coping, threat appraisal and beliefs in understanding and responding to fear of victimization: applications to a male prisoner sample. Law and Human Behaviour, 35, 306-315.

Ireland, J.L. (2012) Understanding bullying among younger prisoners: Recent research and introducing the Multifactor Model of Bullying in Secure Settings. International Journal of Adolescent Medicine and Health, 24, 1, 63-68.

Ireland, J.L., and Archer, J. (2004) Association between measures of aggression and bullying among juvenile and young offenders. Aggressive Behaviour, 30, 29-42.

Ireland, J. L., \& Ireland, C. A. (2008). Intra-group aggression among prisoners: Bullying intensity and exploration of victim-perpetrator mutuality. Aggressive Behaviour, 34, $76-87$

Ireland, J.L., \& Monaghan, R. (2006). Behaviours indicative of bullying among young and juvenile male offenders: A study of perpetrator and victim characteristics. Aggressive Behaviour, 32, 172-180.

Ireland, J. L. and Murray, E.G. (2005) Social problem solving and bullying: are prison bullies really impaired problem solvers? In Ireland (Ed) Bullying in Prison: Innovations in research and theory. Devon: Willan Publishing. 
Ireland, J. L., \& Power, C. L. (2009). Fear of bullying among prisoners: Association with experience, psychological distress and respondent sex. Journal of Aggression Conflict and Peace, 1, 22-36

Ireland, J.L. and Qualter, P. (2008) Bullying and social and emotional loneliness in a sample of adult male prisoners. International Journal of Law and Psychiatry, 31, 19-29.

López-Pérez, B., Hanoch, Y., Holt, K., Gummerum, M. (2015). Cognitive and affective empathy, personal belief in a just world, and bullying among offenders, Journal of Interpersonal Violence, 32: 2591 - 2604

Norman, P., Boer, H., and Sedel, E.R. (2005) Protection motivation theory. In: M. Conner \& P. Norman (Eds.), Predicting Health Behaviour: Research and Practice with Social Cognition Models. Open University Press, Maidenhead, pp. 81-126.

Palmer, E.J., and Thakordas, V. (2005) Relationship between bullying scores on the BussPerry Aggression Questionnaire among imprisoned male offenders. Aggressive Behaviour, 31, 56-6.

Power, K. G., Dyson, G. P. and Wozniak, E. (1997), Bullying among Scottish young offenders: Inmates' self-reported attitudes and behaviour. Journal of Community Applied Social Psychology, 7: 209-218.

South, C. R., and Wood, J. (2006). Bullying in prisons: The importance of perceived social status, prisonization, and moral disengagement. Aggressive Behaviour, 32, 490-501.

Turner, P., \& Ireland, J. L. (2010). Do personality characteristics and beliefs predict intragroup bullying between prisoners? Aggressive Behaviour, 36, 261-270.

Viljoen, J. L., O'Neill, M. L. and Sidhu, A. (2005), Bullying behaviors in female and male adolescent offenders: prevalence, types, and association with psychosocial adjustment. Aggressive. Behaviour, 31: 521-536 
Table 1. Mean scores on Aggression Questionnaire (AQ) across bullying group

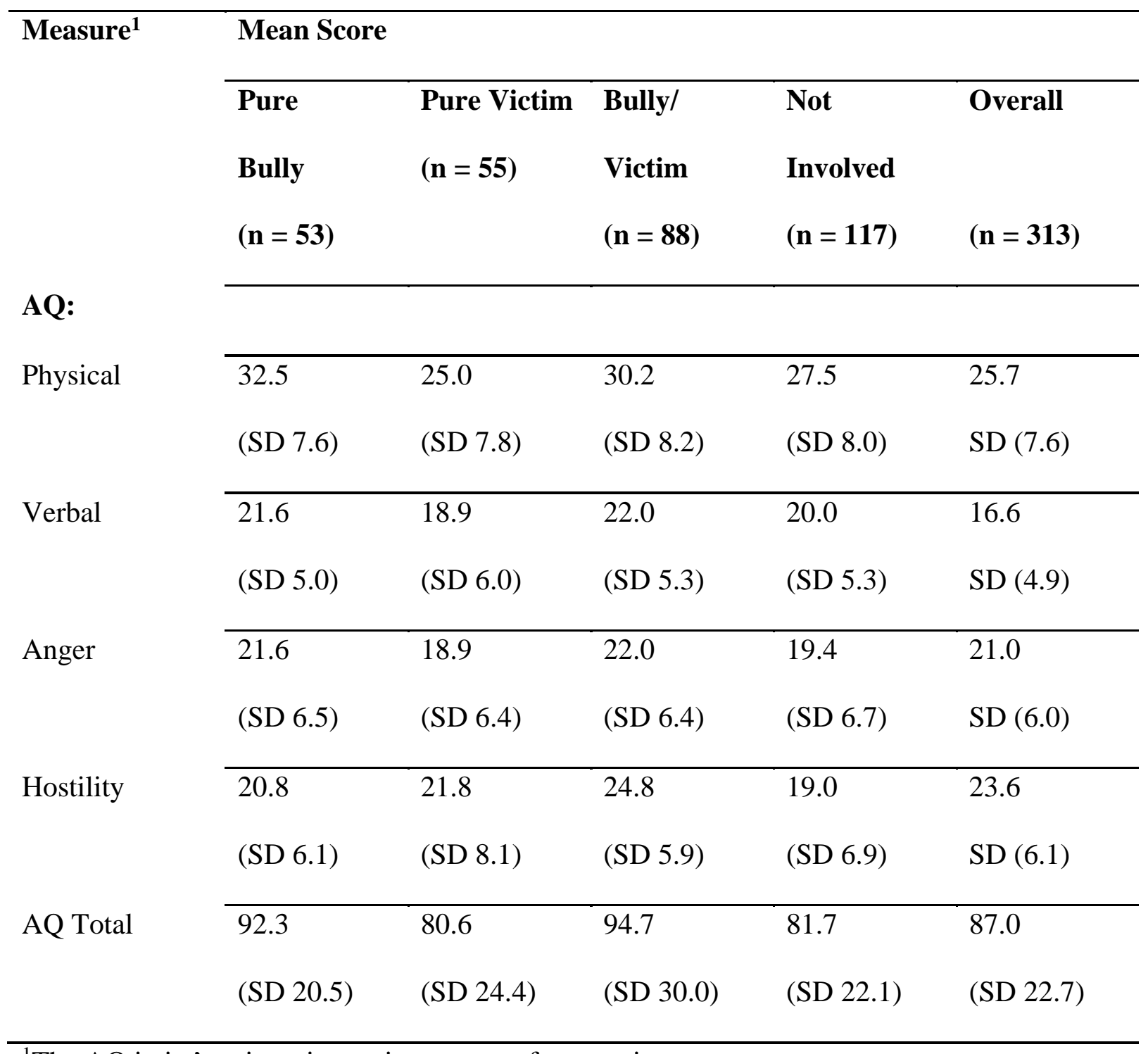

${ }^{1}$ The AQ in its' entirety is a trait measure of aggression. 
Table 2. TAB-R results: How a threat of aggression should be responded to and how others are considered likely to respond (i.e. normative beliefs).

Results are shown across bully group and overall.

\begin{tabular}{|c|c|c|c|c|c|c|}
\hline & & & Mean score & & & Significance \\
\hline & $\begin{array}{l}\text { Pure Victims } \\
\text { (SD) }[n]\end{array}$ & $\begin{array}{l}\text { Pure Bullies } \\
\text { (SD) }[n]\end{array}$ & $\begin{array}{l}\text { Bully/Victims } \\
\text { (SD) }[n]\end{array}$ & $\begin{array}{c}\text { Not } \\
\text { Involved (SD) } \\
{[n]}\end{array}$ & $\begin{array}{l}\text { Overall } \\
\text { (SD) }[n]\end{array}$ & $\begin{array}{c}\text { level across } \\
\text { groups } \\
\text { sig (partial eta } \\
\text { squared) }\end{array}$ \\
\hline $\begin{array}{l}\text { TAB-R: Helpfulness of the followin } \\
\text { if being aggressed against: }\end{array}$ & & & & & & \\
\hline Seeking help from staff & $1.5(1.6)[49]$ & $1.0(1.5)[46]$ & $1.5(1.4)[80]$ & $1.2(1.6)[93]$ & $\begin{array}{l}1.3 \quad(1.5) \\
{[268]}\end{array}$ & $.41(.01)$ \\
\hline Being aggressive towards the bully & $1.8(1.6)[51]$ & $2.3(1.6)[46]$ & $2.4(1.6)[79]$ & $1.9(1.7)[94]$ & $\begin{array}{l}2.1 \quad(1.7) \\
{[270]}\end{array}$ & $.14(.02)$ \\
\hline
\end{tabular}




\begin{tabular}{|c|c|c|c|c|c|c|c|}
\hline Seeking help from another prisoner/s & $1.2(1.4)[50]$ & $1.3(1.4)[46]$ & $1.7(1.5)[79]$ & $1.2(1.5)[93]$ & $\begin{array}{l}1.4 \\
{[268]}\end{array}$ & $(1.5)$ & $.06(.03)$ \\
\hline Trying to reason with the bully & $.96(1.5)[50]$ & $.54(1.0)[46]$ & $1.0(1.2)[81]$ & $.53(1.1)[93]$ & $\begin{array}{l}.75 \\
{[270]}\end{array}$ & (1.2) & $.03(.03)^{*}$ \\
\hline Try to ignore it & $1.4(1.7)[49]$ & $1.1(1.5)[46]$ & $1.1(1.4)[80]$ & $.83(1.4)[94]$ & $\begin{array}{l}1.1 \\
{[269]}\end{array}$ & $(1.5)$ & $.14(.02)$ \\
\hline Avoid contact with other prisoners & $1.1(1.5)[48]$ & $.52(1.0)[94]$ & $.85(1.3)[80]$ & $.46(1.1)[94]$ & $\begin{array}{l}.71 \\
{[268]}\end{array}$ & (1.3) & $.02(.04)^{*}$ \\
\hline Staying in my cell when I should be out & $1.0(1.5)[49]$ & $.48(1.1)[46]$ & $.78(1.3)[81]$ & $.37(.97)[94]$ & $\begin{array}{l}.63 \\
{[270]}\end{array}$ & $(1.2)$ & $.01(.04)^{*}$ \\
\hline $\begin{array}{l}\text { Putting on "an act" by pretending to be tougher } \\
\text { than you are }\end{array}$ & $1.1(1.5)[50]$ & $.61(1.2)[46]$ & $1.2(1.5)[80]$ & $.49(1.1)[94]$ & $\begin{array}{l}.83 \\
{[270]}\end{array}$ & $(1.3)$ & $.00(.05)^{*}$ \\
\hline Being aggressive towards another prisoner & $1.1(1.4)[50]$ & $1.7(1.5)[46]$ & $1.5(1.5)[81]$ & $.90(1.3)[95]$ & $\begin{array}{l}1.3 \\
{[272]}\end{array}$ & $(1.4)$ & $.00(.05)^{*}$ \\
\hline
\end{tabular}




\begin{tabular}{|c|c|c|c|c|c|c|c|}
\hline Just giving up and doing what the bully wants & $.82(1.4)[50]$ & $.24(.74)[46]$ & $.56(1.2)[80]$ & $.19(.75)[94]$ & $\begin{array}{l}.42 \\
{[270}\end{array}$ & $(1.1)$ & $.01(.04)^{*}$ \\
\hline Threatening to self-harm & $.56(1.2)[50]$ & $.17(.61)[46]$ & $.43(1.1)[81]$ & $.26(.82)[94]$ & $\begin{array}{l}.35 \\
{[271]}\end{array}$ & $(.95)$ & $.32(.01)$ \\
\hline Self-harming & $.78(1.3)[50]$ & $.30(.94)[46]$ & $.43(1.1)[81]$ & $.27(.82)[94]$ & $\begin{array}{c}.39 \\
{[268}\end{array}$ & $(1.0)$ & $.15(.02)$ \\
\hline Seeking help from staff & $.12(.33)[49]$ & $.02(.15)[46]$ & $.10(.30)[70]$ & $.17(.37)[84]$ & $\begin{array}{l}.11 \\
{[249}\end{array}$ & $(.32)$ & $.10(.03)$ \\
\hline Being aggressive towards the bully & $.39(.49)[49]$ & $.76(.43)[46]$ & $.50(.50)[70]$ & $.58(.50)[84]$ & $\begin{array}{l}.55 \\
{[249}\end{array}$ & $(.50)$ & $.00(.06)^{*}$ \\
\hline Seeking help from another prisoner/s & $.02(.14)[49]$ & $.04(.21)[46]$ & $.17(.38)[70]$ & $.05(.21)[84]$ & $\begin{array}{l}.08 \\
{[249}\end{array}$ & $(.27)$ & $.01(.05)^{*}$ \\
\hline
\end{tabular}




\begin{tabular}{|c|c|c|c|c|c|c|c|}
\hline Trying to reason with the bully & $.06(.24)[49]$ & $00(.00)[49]$ & $.11(.32)[70]$ & $.02(.15)[84]$ & $\begin{array}{l}.05 \\
{[249]}\end{array}$ & $(.22)$ & $.02(.04)^{*}$ \\
\hline Try to ignore it & $.24(.43)[49]$ & $.11(.31)[46]$ & $.17(.38)[70]$ & $.17(.37)[84]$ & $\begin{array}{l}.17 \\
{[249]}\end{array}$ & $(.38)$ & $.38(.01)$ \\
\hline Avoid contact with other prisoners & $.10(.31)[49]$ & $00(.00)[49]$ & $.01(.12)[70]$ & $.05(.21)[84]$ & $\begin{array}{l}.04 \\
{[249]}\end{array}$ & $(.20)$ & $.04(.03)^{*}$ \\
\hline Staying in my cell when I should be out & $.12(.33)[49]$ & $.04(.21)[46]$ & $.07(.26)[70]$ & $00(.00)[49]$ & $\begin{array}{l}.05 \\
{[249]}\end{array}$ & $(.22)$ & $.02(.04)^{*}$ \\
\hline $\begin{array}{l}\text { Putting on "an act" by pretending to be tougher } \\
\text { than you are }\end{array}$ & $.04(.20)[49]$ & $.02(.15)[46]$ & $.04(.20)[70]$ & $00(.00)[49]$ & $\begin{array}{l}.02 \\
{[249]}\end{array}$ & $(.15)$ & $.29(.02)$ \\
\hline Being aggressive towards another prisoner & $.02(.14)[49]$ & $.07(.25)[46]$ & $.09(.28)[69]$ & $.05(.21)[84]$ & $\begin{array}{l}.57 \\
{[248]}\end{array}$ & (.23) & $.46(.01)$ \\
\hline Being aggressive towards staff & $.00(.00)[49]$ & $.04(.21)[46]$ & $.03(.17)[70]$ & $.02(.15)[84]$ & $\begin{array}{l}.02 \\
{[249]}\end{array}$ & $(.15)$ & $.58(.01)$ \\
\hline
\end{tabular}




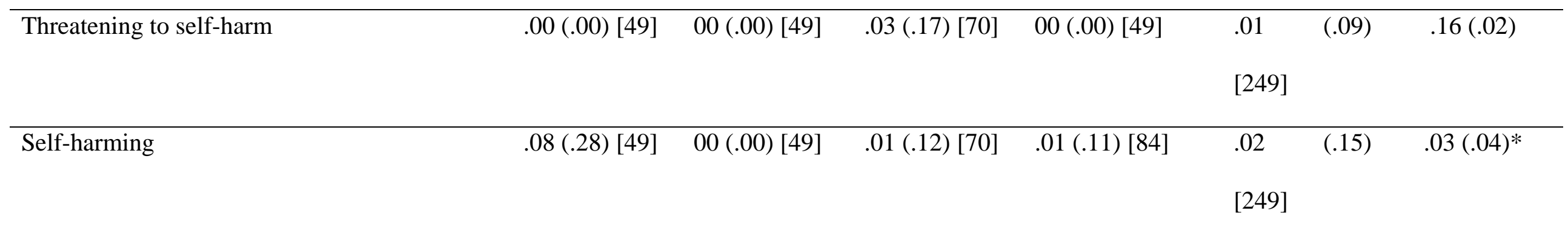

\section{TAB-R: How others would expect me to}

\section{behave (normative beliefs):}

\begin{tabular}{|c|c|c|c|c|c|c|c|}
\hline To seek help from staff & $.97(1.4)[46]$ & $.45(.95)[44]$ & $.91(1.4)[75]$ & $.85(1.4)[81]$ & $\begin{array}{l}.82 \\
{[246]}\end{array}$ & (1.3) & $.37(.01)$ \\
\hline Being aggressive towards bully & $2.2(1.7)[46]$ & $3.1(1.3)[43]$ & $3.0(1.5)[72]$ & $2.6(1.7)[84]$ & $\begin{array}{l}2.7 \\
{[245]}\end{array}$ & (1.6) & $.00(.05)^{*}$ \\
\hline Seeking help from another prisoner/s & $1.0(1.4)[45]$ & $.84(1.3)[44]$ & $1.7(1.5)[75]$ & $.85(1.2)[80]$ & $\begin{array}{l}1.1 \\
{[244]}\end{array}$ & (1.4) & $.00(.07)^{*}$ \\
\hline
\end{tabular}




\begin{tabular}{|c|c|c|c|c|c|c|c|}
\hline Trying to reason with the bully & $1.0(1.3)[44]$ & $.50(.97)[44]$ & $1.0(1.3)[75]$ & $.72(1.2)[81]$ & $\begin{array}{l}.82 \\
{[244]}\end{array}$ & $(1.2)$ & $.12(.03)$ \\
\hline Try to ignore it & $1.3(1.5)[46]$ & $.77(1.3)[44]$ & $1.2(1.5)[75]$ & $.96(1.4)[81]$ & $\begin{array}{l}1.1 \\
{[246]}\end{array}$ & (1.4) & $.54(.01)$ \\
\hline Avoid contact with other prisoners & $.87(1.3)[45]$ & $.39(.87)[44]$ & $.67(1,2)[76]$ & $.61(1.2)[82]$ & $\begin{array}{l}.64 \\
{[247]}\end{array}$ & $(1.1)$ & $.27(.02)$ \\
\hline Staying in my cell when I should be out & $.70(1.2)[46]$ & $.43(.95)[44]$ & $.68(1.3)[76]$ & $.41(.92)[83]$ & $\begin{array}{l}.55 \\
{[249]}\end{array}$ & $(1.1)$ & $.48(.01)$ \\
\hline $\begin{array}{l}\text { Putting on "an act" by pretending to be tougher } \\
\text { than you are }\end{array}$ & $.89(1.3)[44]$ & $.68(1.2)[44]$ & $1.3(1.5)[74]$ & $.93(1.4)[82]$ & $\begin{array}{l}.98 \\
{[244]}\end{array}$ & $(1.4)$ & $.11(.03)$ \\
\hline Being aggressive towards another prisoner & $1.1(1.4)[46]$ & $2.0(1.8)[45]$ & $2.0(1.6)[75]$ & $1.3(1.6)[83]$ & $\begin{array}{l}1.6 \\
{[249]}\end{array}$ & $(1.6)$ & $.00(.07)^{*}$ \\
\hline Being aggressive towards staff & $.74(1.1)[46]$ & $1.1(1.5)[44]$ & $1.0(1.4)[74]$ & $.56(1.1)[81]$ & $\begin{array}{l}.82 \\
{[245]}\end{array}$ & (1.3) & $.06(.03)$ \\
\hline
\end{tabular}




$.39(.97)[44$

[44]

.45 (1.1) [45]

$.36(.90)$ [83]

.44


